\title{
Use of fuel cell stacks to achieve high altitudes in light unmanned aerial vehicles
}

\author{
Jordi Renau ${ }^{1}$, Antonio Lozano ${ }^{2, *}$, Jorge Barroso ${ }^{2}$, José Miralles ${ }^{1}$, Jesús Martín ${ }^{2}$, \\ Fernando Sánchez ${ }^{1}$, Félix Barreras ${ }^{2}$ \\ 1 UCH CEU. Universidad CEU Cardenal Herrera. C/ San Bartolomé, 55, 461150- Alfara del \\ Patriarca, Valencia. SPAIN \\ 2 LIFTEC, CSIC - Universidad de Zaragoza. Maria de Luna 10, 50018 - Zaragoza. SPAIN
}

\begin{abstract}
A study is presented to determine if substituting an internal combustion engine (ICE) by an electric motor powered by a fuel cell stack can be a viable option to increase the service ceiling of an available light unmanned aerial vehicle (UAV), extending it to $10,000 \mathrm{~m}$. As a first condition, the stack has to be capable of supplying the minimum power required for horizontal leveled flight at this altitude, which is a function of the UAV total mass. A second step examines if the UAV can transport the energy required to reach the desired service ceiling without exceeding the maximum mass that can be loaded, considering that both hydrogen and oxygen have to be carried on-board. A particularly light PEM fuel cell stack is proposed as a suitable power source. A realistic system is described to store the required amount of reactant gases maintaining the mass below the allowable limits. Results indicate that with its aerodynamic characteristics, the UAV should be capable of ascending up to $10,000 \mathrm{~m}$ with the described fuel cell and gas storage system. Some multivariable maps that include service ceiling, total payload and required power are provided to perform this type of analysis.
\end{abstract}

Keywords: PEM fuel cell, Hydrogen, High-temperature, UAV, Aerodynamics

\footnotetext{
*Corresponding author. E-Mail: alozano@litec.csic.es
} 


\section{Nomenclature}

\section{Latin alphabet}

A constant value

$A R \quad$ wing aspect ratio

$b \quad$ wingspan (m)

$B$ constant value

c constant value

$C_{L} \quad$ lift coefficient

$C_{\text {Lmax }}$ maximum lift coefficient

$C_{D} \quad$ drag coefficient

$C_{D O} \quad$ parasitic drag coefficient

$D \quad$ drag force $(\mathrm{N})$

$e \quad$ Oswald efficiency

$g \quad$ gravity acceleration $\left(\mathrm{m} \mathrm{s}^{-2}\right)$

$h \quad$ height above the sea level (m)

$\mathrm{k}$ ratio of indicated power

$L \quad$ lift force (N)

$n \quad$ weight factor

$M_{F} \quad$ aircraft frame mass $(\mathrm{kg})$

$M_{H 2} \quad$ mass of hydrogen storage system $(\mathrm{kg})$

$M_{O 2}$ mass of oxygen storage system $(\mathrm{kg})$

$M_{\text {Total }}$ total mass of the storage system $(\mathrm{kg})$

$p_{h} \quad$ pressure at the given height $(\mathrm{Pa})$

$p_{S L} \quad$ pressure at the sea level $(\mathrm{Pa})$

$P \quad$ aircraft power (W)

$P_{\text {Prop }} \quad$ propeller power (W)

$P_{S L} \quad$ aircraft power at sea level (W)

$P_{F C} \quad$ fuel cell power $(\mathrm{W})$

$R C \quad$ rate of climb $\left(\mathrm{m} \mathrm{s}^{-1}\right)$

$S \quad$ wing surface $\left(\mathrm{m}^{2}\right)$

$T_{h} \quad$ temperature at the given height (K)

$T_{S L} \quad$ temperature at the sea level (K)

$T \quad$ thrust force (N)

$v \quad$ aircraft velocity $\left(\mathrm{m} \mathrm{s}^{-1}\right)$

$v_{\text {stall }} \quad$ stall (minimum) velocity $\left(\mathrm{m} \mathrm{s}^{-1}\right)$

$V_{H 2} \quad$ volume of stored hydrogen (1)

$V_{O 2} \quad$ volume of stored oxygen (1)

W aircraft weight $(\mathrm{kg})$

\section{Greek letters}

$\alpha \quad$ attack angle

$\beta \quad$ flight angle when $T$ y $v$ are aligned

$\delta \quad$ power adjustment value

$\gamma \quad$ trajectory angle

$\eta_{D C D C}$ efficiency of the DC/DC converter

$\eta_{m} \quad$ engine mechanical efficiency

$\eta_{\text {motor }}$ efficiency of the electric motor

$\eta_{\text {trans }}$ efficiency of the transmission

$\eta_{\text {Prop }}$ efficiency of the propeller

$\theta \quad$ pitch or elevation angle

$\kappa \quad$ angle between $\tau_{e}$ and the longitudinal axis

$\rho \quad$ density $\left(\mathrm{kg} \mathrm{m}^{-3}\right)$

$\tau_{e} \quad$ thrust force $(\mathrm{N})$ 


\section{Introduction}

Development of aerial vehicles powered by fuel cells responds to the request of finding new ways to supply energy with high efficiency and low pollutant emissions. The possibility of using fuel cell stacks in power units of crewed aircrafts is still a future objective, but manufacturing unmanned aerial vehicles (UAVs) with these power sources can be achieved with current technology. Depending on flight ceiling and duration, size and weight, UAVs can be divided in micro, tactic, strategic and UAVs for special tasks [1]. Potential applications of these devices are multiple, both in civil or military missions. The fact that they can be light, without human pilots and that most of their controls are electrically driven, makes them an ideal test bed for powerplants based on fuel cells. In the last years, some papers have reported successful flight tests of small UAVs with electricity supplied by fuel cells [2-4]. However, most of this still reduced number of cases has been limited to short flights at low altitude.

High altitude flights of small UAVs pose some specific challenges related to the particular conditions of the stratosphere. Very low ambient temperatures and pressures can limit the operation of atmospheric reciprocating internal combustion engines (ICE). Unfortunately, ICEs with small cylinder capacity are not suitable to incorporate systems to increase the intake pressure. As their efficiency is already quite low, this power loss as a function of altitude becomes much more critical than that in large engines, where this effect can be balanced with a compressor. A combination of electric motors with fuel cells can be an advantageous alternative to mini-ICEs. Efficiency of electric motors is far better than that of an ICE, for any rpm range. Besides, fuel cells can be designed to operate at high altitudes, taking into account the special requirements for this application. As in all types of aircraft and flight conditions, weight is an essential issue. Fuel cells are required to be as light as possible, but the need to carry on-board bottles to store the reactant gases or alternative systems to generate them in situ has also to be taken into account. If the UAV has to reach high altitudes, not only hydrogen but also oxygen has to be transported. This is so because oxygen 
concentration in the stratosphere is too low to adopt open cathode configurations. Besides, atmospheric temperature has also to be considered in the design of the cooling system.

The objective of this research is to provide adequate tools to determine if for some specific aerodynamic characteristics, a light UAV will be capable of reaching an altitude of 10,000 m powered by a fuel cell and carrying onboard the required amount of reactant gases.

\section{Determination of the minimum required power}

In daily operation, an aircraft engine can provide a certain maximum power for a determinate time (depending on fuel reserves). According to it, the pilot has to program the flight, adjusting velocity, height, or climbing and descending strategies so that neither maximum power nor flying time are exceeded. In the present case, a fuel cell stack is to be adapted to a specific UAV, so, first, the minimum required power has to be determined. To calculate it, basic aerodynamic equations will be used, in the understanding that this work does not pretend to study in depth the theory of aircraft. Initially, an UAV with the following characteristics will be considered:

- Total airframe mass: $3.0 \mathrm{~kg}$

- Service ceiling: $10,000 \mathrm{~m}$

- Wing surface area $(S): 0.8 \mathrm{~m}^{2}$

- Wingspan $(b): 4 \mathrm{~m}$

- Wing aspect ratio $(A R): 20$

- Wing profile: S4233 (mod.)

- $\quad$ Lift coefficient $\left(C_{\text {Lmax }}\right): 1.1$

- Parasitic drag coefficient $\left(C_{D 0}\right): 0.02$

- Oswald efficiency (e): 0.65

- Maximum lift/drag ratio: 20

- Wing loading: $<20 \mathrm{~kg} \mathrm{~m}^{-2}$ 
- Weight factor $(n):>4$

The subsequent analysis will determine if this aircraft is capable of reaching high altitudes with a fuel cell stack of a specific power.

A UAV can fly with six degrees of freedom that have to be controlled: displacement along the three axes and rotations around them. Primary control elements are ailerons in the front wings, elevators on the horizontal tail and rudder in the vertical tail. To simplify the calculations, it will be assumed that the UAV only moves along its longitudinal and normal axes. The propeller, moved by the engine, generates the thrust required to displace the aircraft. In the sketch in Fig. 1, thrust is represented as $\tau_{e}$, and is, in general, a non-centered force, deviated an angle $\kappa$ with respect to the longitudinal axis.

Thrust can be represented as a force $T$ applied on the coordinate system origin, which is generally chosen to be coincident with the aircraft center of gravity. Its contribution to the total momentum $M$ has also to be considered. The rest of the total momentum is due to forces induced by the tail, and the deviation between the trajectory angle $(\gamma)$ and the pitch or elevation angle $(\theta) . M$ also depends on the aircraft design. Aerodynamic forces acting during the flight are lift, $L$, and drag, $D$. Both are generated by the interaction of the moving airplane with the atmospheric air. Their magnitudes are

$$
\begin{aligned}
& L=\frac{1}{2} \rho v^{2} S C_{L} \\
& D=\frac{1}{2} \rho v^{2} S C_{D}
\end{aligned}
$$

where $S$ is the wing surface and $\rho$ is the air density. According to the standard atmosphere (ISA), $\rho$ decreases with altitude $h$ as

$$
\rho=\left(\frac{A-h}{B}\right)^{c}
$$


expression applicable up to $10,000 \mathrm{~m}$ and where $A$ is $44,330.769 ; B$ is $42,266.482$, and $c$ is 4.2559 . $C_{L}$ and $C_{D}$ are the drag and lift coefficients, which depend on the aerodynamic characteristics of the aircraft. They are related by

$$
C_{D}=C_{D 0}+\frac{C_{L}^{2}}{\pi e A R}
$$

where $C_{D O}$ is the parasitic drag coefficient, $A R$ is the wing aspect ratio which is the ratio between wingspan squared and wing surface, and $e$ is the Oswald efficiency.

In the case of UAVs moved by a propeller, $T$ normally coincides with the longitudinal stability axis [5]. Hence, it will be assumed that thrust $T$ and velocity $v$ have the same direction and sign, in such a way that $\theta=\gamma=\beta$. This implies that UAV displacement is only allowed along $x$ and $z$ axes. This assumption greatly simplifies the set of equations to estimate the required power for the flight because there is an analytical solution for the three different segments that will be considered: ascending, cruising and descending flight. From a balance of the different forces (thrust, drag and lift) and with the geometric characteristics of the UAV, the resulting equations are summarized in Table 1.

In this table, $R C$ denotes the rate of climb, given by the vertical velocity,

$$
R C=v \cdot \sin (\theta)
$$

The minimum required power for the UAV to fly at a certain altitude will be that for steady horizontal flight, where thrust is equal to drag, and lift is equal to the aircraft weight $(W)$. The minimum velocity to achieve this condition is the stall velocity, expressed as

$$
v_{\text {stall }}=\sqrt{\frac{2 W}{\rho C_{L \max } S}}
$$

Then, the minimum power will be

$$
P_{\min }=T_{\min } v_{\text {stall }}=\frac{1}{2} \rho v_{\text {stall }}^{3} S C_{D}=\sqrt{\frac{2 W}{\left(\frac{A-h}{B}\right)^{c} C_{L \max } S}} W \frac{C_{D}}{C_{L}}
$$


where air density has been substituted by eq. (3).

This is a limiting power, in the sense that if the power source is not capable of supplying it, the UAV will not have enough lift to fly at the desired service ceiling. It is then a necessary condition, but it is not sufficient. This is because for a given total UAV mass, the available energy might be lower than that required to complete the ascent to the final altitude. Increasing the energy will rise the total mass, which in turn will modify the needed power. Service ceiling, total payload and required power are coupled. To establish compatible values for these parameters, an iterative procedure has to be followed. However, finding a satisfactory solution is not always possible.

It has to be noted that the above equations correspond to thrusting power. If it is going to be supplied by an ICE, there will be a power loss as a function of height given by

$$
P=\delta P_{S L}
$$

where subscript $S L$ indicates sea level and $\delta$ is a power adjustment value. According to the ISO 3046-1 standard [6], $\delta$ is given by

$$
\delta=k-0.7(1-k)\left(\frac{1}{\eta_{m}}-1\right)
$$

where $\eta_{m}$ is the engine mechanical efficiency (typically ranging between 0.7 and 0.9 ) and $k$ is the ratio of indicated power. For an Otto (gasoline) atmospheric engine, it can be expressed as

$$
k=\left(\frac{p_{h}}{p_{S L}}\right)^{0.86}\left(\frac{T_{S L}}{T_{h}}\right)^{0.55}
$$

where $p$ is absolute pressure and $T$ is the absolute temperature at the sea level (subscript $S L$ ) and at the given height (subscript $h$ ), respectively. Effects of air humidity have been neglected in this equation because their effect is minor compared to that due to the variation in pressure and temperature $[7,8]$. 
Opposite to ICE, the power supplied by a fuel cell will be constant with altitude. However, the actual power available in the propeller will be decreased due to a series of efficiency factors as given by

$$
P_{\text {prop }}=P_{F C}\left(\eta_{D C / D C} \eta_{\text {motor }} \eta_{\text {trans }} \eta_{\text {prop }}\right)
$$

where the efficiency of the DC/DC converter $\eta_{D C / D C}$ is estimated to be $90 \%$, that of the electric motor $\eta_{\text {motor }}$ is estimated in $95 \%$, and the transmission $\eta_{\text {trans }}$ is considered to be $100 \%$ efficient. Finally, an efficiency $\eta_{\text {prop }}$ of $80 \%$ will be assigned to the propeller, according to our own tests.

With all these values, the total efficiency for the powertrain is $68.4 \%$, although to have a safety margin, a lower figure of $65 \%$ will be used in further calculations. Establishing a maximum altitude of 10,000 $\mathrm{m}$ and applying eq. (7), a relationship between minimum fuel cell power and UAV mass can be obtained, as shown in Fig. 2.

As the required power is a function of the UAV mass, this value has to be estimated in order to decide if a specific fuel cell is capable of driving the aircraft to a desired altitude. There are some elements whose mass can be considered fixed for a given UAV. They include airframe (fuselage, wings and tail), electric motor, control electronics, fuel cell and gas manifolds. However, the mass of the reactant gas storage system (considering gas and bottles) depends on the flight strategy and the maximum height to be reached.

For the original prototype, the total mass of its structure adding fuselage, wings and tail is 3 $\mathrm{kg}$. Having in mind that some modifications could be needed to adapt the fuel cell system, a safety value of $0.5 \mathrm{~kg}$ will be added, resulting in a total mass of $3.5 \mathrm{~kg}$. The mass of the electric motor and control electronics can be estimated in $1.6 \mathrm{~kg}$. Finally, a mass of $4 \mathrm{~kg}$ will be assigned to the fuel cell, as will be discussed later. The mass of the gas storage system depends on the flight range. However, its highest value is limited by the maximum payload that can be transported by the aircraft. For the current prototype, this limit should not exceed $20 \mathrm{~kg} \mathrm{~m}^{-2}$. As the wing surface area is $0.8 \mathrm{~m}^{2}$, the total UAV mass can reach up to $16 \mathrm{~kg}$, of which $9 \mathrm{~kg}$ corresponds to the fixed elements. 
To have an initial estimate, a fuel cell of $650 \mathrm{~W}$ will be considered, which, using eq. (11), will supply a power of $422.5 \mathrm{~W}$ to the propeller. For this power and applying again eq. (7), a maximum altitude can be calculated for a given UAV total mass (see Fig. 3). If 10,000 m are to be reached, the maximum total mass is around $21 \mathrm{~kg}$, and the calculated mass $(16 \mathrm{~kg})$ is below this limit.

Required thrusting power as a function of service ceiling for a $16 \mathrm{~kg}$ aircraft in a constant $R C$ ascent is presented in Fig. 6. The decreasing dotted line crossing the plot shows the net power available in the propeller if it is supplied by an ICE, calculated with equations (8-10). Compared to the ICE, the power supplied by a fuel cell would be constant with altitude, and this is why it appears in Fig. 4 as a straight horizontal dotted line. Considering only power supply efficiency, it is clear that a fuel cell will be a much better choice than an ICE with atmospheric intake pressure.

Further requirements related to the available energy will now be discussed.

\section{Service ceiling and available energy}

Up to now, to determine the minimum required power, flight duration has not been considered. Taking into account the energy required for the ascending flight adds a new constraint that can be used to gage the gas storage system and to obtain the final UAV mass. To climb up to $10,000 \mathrm{~m}$ different flight strategies can be followed, each one requiring a different thrusting power. A possibility is to ascend at a constant rate of climb $R C$ ( $c f$. eq. (5)). It is clear that with this option, the climb angle has to decrease with altitude, as $v$ increases due to the change in density. For this reason, the required power has also to be increased as the aircraft goes up. Consequently, the power that has to be supplied increases with service ceiling.

Alternatively, the ascension can be accomplished for a constant propeller power, where $R C$ is maximized at each altitude. With this strategy, $R C$ decreases with height, because part of the power has to be used to increase the velocity to compensate for the lift loss due to the change in the air density. However, climbing time is minimized, and the total required energy is also lower. Figure 5 
shows the variation of $R C$ and power as a function of altitude for the two climb modes described. For constant $R C$ (dotted lines), the maximum value that can be achieved for a propeller power of $422.5 \mathrm{~W}$ is $0.9 \mathrm{~m} \mathrm{~s}^{-1}$.

Still, energy requirements for constant power ascension are quite demanding. This can be shown plotting iso-energy curves relating UAV mass and altitude (Fig. 6). All the curves except the dotted line have been calculated assuming the maximum possible $R C$ for a given available energy. The dotted line is the same one as that in Fig. 3, and corresponds to the maximum height at which the UAV can have a horizontal leveled flight for a fixed power of $422.5 \mathrm{~W}$.

It has to be noted that lines in Fig. 6 correspond to the energy consumed in the propeller. To relate them to energy to be stored in the gas bottles, efficiency of all the powertrain elements $(65 \%)$ has to be taken into account. From Fig. 6 it can be established that for a $16 \mathrm{~kg}$ UAV about $930 \mathrm{Wh}$ are required to reach the $10,000 \mathrm{~m}$ target. Considering the mass of the different elements described in the previous Section, the powertrain demands an energy density around $110 \mathrm{Wh} \mathrm{kg}^{-1}$.

\section{Fuel cell stack}

Although the procedures presented in this work are general, to obtain numerical results some specific details of the fuel cell stack are required. For this reason, a brief summary of the main characteristics of the stack to be installed in the UAV prototype will be included here. It is a high temperature PEM fuel cell, capable of supplying a maximum power over $700 \mathrm{~W}$, based on commercial MEAs BASF Celtec ${ }^{\circledR}-P 1100$ with an active area of $81.28 \mathrm{~cm}^{2}$. A polarization curve experimentally obtained in our research facilities for a single cell with this MEA is presented in Fig.

7.

For stationary conditions and following the recommendations of the manufacturer, a current density $j=0.3 \mathrm{~A} \mathrm{~cm}^{-2}$ has been considered, which yields a total current of $24.38 \mathrm{~A}$. According to the 
polarization curve, a voltage of $0.54 \mathrm{~V}$ per cell is obtained for this current. Then, stacking 50 cells, the resulting fuel cell power is $658 \mathrm{~W}$.

As already demonstrated, reducing the mass is essential to increase the service ceiling for a given power. To lighten the stack, it will be constructed with monopolar aluminum plates, coated with chromium nitride by physical vapor deposition $[9,10]$. With these elements, the total stack mass is $3.86 \mathrm{~kg}$. This mass could be further reduced using lighter materials e.g. some magnesium alloy for monopolar plates.

Knowing the stack configuration and the supplied power, gas consumption can be determined. This is required to evaluate the capacity of the gas storage system. Actual consumption calculation has to include the efficiency of the powertrain, already estimated in $65 \%$, plus the efficiency of the electrochemical conversion, that is assumed to be $40 \%$ (Fig. 8).

With specific consumptions of $0.0376 \mathrm{~g}_{\mathrm{H}_{2}}(\mathrm{~A} \cdot \mathrm{h})^{-1}$ for hydrogen and $0.2985 \mathrm{~g}_{\mathrm{O}_{2}}(\mathrm{~A} \cdot \mathrm{h})^{-1}$ for oxygen in each cell, and respective stoichiometric factors of 1.0 and 1.2, the amount of gases needed for a flight can be obtained once its duration and the expression of $P_{F C}$ as a function of time are known.

\section{Gas storage system}

As stated in the introduction, if the UAV has to fly to high altitudes, both hydrogen and oxygen have to be transported onboard. Establishing a maximum stack power of $650 \mathrm{~W}$ and a constant power ascension strategy, flight duration to climb up to $10,000 \mathrm{~m}$ is $2.2 \mathrm{~h}(2.8 \mathrm{~h}$ ascending at a constant $R C$ of $\left.0.88 \mathrm{~m} \mathrm{~s}^{-1}\right)$. Hence, $106 \mathrm{~g}$ of $\mathrm{H}_{2}(1176 \mathrm{Nl})$ and $960 \mathrm{~g}$ of $\mathrm{O}_{2}(721 \mathrm{Nl})$ will be needed.

Considering the compressibility of each one of the reactant gases, the energy required for the ascending flight can be represented as a gas volume for a certain pressure. This is shown in Fig. 9 for gases stored at a pressure of 500 bar. 
As displayed in Table 2, there are different types of commercial gas cylinders suitable to store these amounts of gas. ISO/TS 15869:2009 Standard [11] classifies pressurized hydrogen cylinders depending on their manufacturing materials. Type I bottles are all metal and their density is too high (from $1.0 \mathrm{~kg} \mathrm{l}^{-1}$ to $1.5 \mathrm{~kg} \mathrm{l}^{-1}$ ). Types II and III cylinders have metallic liners and wrapped composite in the hoop (circumferential) directions (Type II) or over the entire sidewall and dome ends using the filament winding machine (Type III) [12]. Their density ranges from $1.3 \mathrm{~kg} \mathrm{l}^{-1}$ to $0.65 \mathrm{~kg} \mathrm{l}^{-1}$ for Type II, and from $0.45 \mathrm{~kg} \mathrm{l}^{-1}$ to $0.3 \mathrm{~kg} \mathrm{l}^{-1}$ for Type III. Although Type II cylinders are very common, they are also discarded because they give an excessively low energy density. Density of Type IV bottles (plastic liner wrapped with composites over the entire sidewall and dome ends by filament winding [12]) is in the same range as that for Type III but they can be filled at higher pressures. In both cases, the total mass is below the initial limit of $7 \mathrm{~kg}$. To calculate it, the mass of the bottles filled with gas has been increased in a $20 \%$ to account for valves and pressure regulators weight. The energy per unit volume has been calculated considering the hydrogen and oxygen cylinders together.

Other storage methods, as metallic hydrides have not been considered, because their specific energy is quite low [13].

All the variables involved in this analysis can be related in a single multivariable plot as the one depicted in Fig. 10, for a fixed volume of hydrogen and a constant $R C$ climbing strategy. The horizontal axis indicates the maximum distance that can be achieved with the available energy. The vertical axis gives the maximum achievable height. The downwards oblique lines stand for different total weight. The nearly diagonal upwards lines correspond to values for constant $R C$ and the nearly vertical lines indicate the minimum aerodynamic power required for the flight for a given constant $R C$. As an example, let's fix the total weight in $16 \mathrm{~kg}$ and a stack power of $650 \mathrm{~W}$ that translates into an available power of $422.5 \mathrm{~W}$ in the propeller (the two red dotted lines). With this input, the maximum ceiling is slightly below $9500 \mathrm{~m}$ (horizontal red arrowed line) at a $R C$ of $0.9 \mathrm{~m} \mathrm{~s}^{-1}$ (diagonal red arrow) and a total flight distance of $270 \mathrm{~km}$ (vertical red arrow). The range (flight 
distance) can be increased at the expense of reducing the ceiling and the $R C$. Increasing either ceiling or $R C$ requires more available energy, i.e. more hydrogen and oxygen. Figure 10 has been generated for a fixed amount of hydrogen (a total volume of 41 stored at 500 bar), but without $a$ priori limiting the available power. When discussing Fig. 4 it has been shown that ascending at constant $R C$ requires more energy than doing it at fixed power. This is why the target $10,000 \mathrm{~m}$ ceiling is not reached (the UAV can only climb up to 9,500 m).

On the contrary, if the ascending flight is performed at constant power, the required ceiling target can be properly achieved. Effectively, if a constant power ascend is fixed, thus varying $R C$ during the flight, the multivariable plot in Fig. 11 can be generated. In this case, $10,000 \mathrm{~m}$ can be reached for $422.5 \mathrm{~W}$, identical total mass of $16 \mathrm{~kg}$ and the same volume of hydrogen with a maximum $R C$ of $0.88 \mathrm{~m} \mathrm{~s}^{-1}$.

Analyzing these data, it is concluded that the UAV should be able to reach the desired altitude. If this would have not been the case, possible actions to improve the situation might include increasing the stack power (adding more cells), increasing the amount of gases carried on-board to have more available energy, or modifying the UAV design so that it could fly with less power. This last option can be achieved, for example, varying the wing profile to improve the values of the drag and lift coefficients, $C_{L}$ and $C_{D}$, or more immediately, increasing the wing surface area $S$. Yet, an increase in $S$ entails increasing the UAV weight and, again, a dead end could be reached. A good approximation is given by [14].

$$
M_{F}=0.569 S^{1.59} A R^{0.71}
$$

where $M_{F}$ is the aircraft frame mass.

\section{Conclusions}

A study has been performed to theoretically determine if substituting an internal combustion engine by an electric motor powered by a fuel cell stack can be a viable option to increase the 
service ceiling of an available light UAV. A target ceiling has been established in 10,000 m. Concentration of oxygen at this altitude is too low to adopt open cathode configurations. Hence, both hydrogen and oxygen have been assumed to be carried onboard. From basic aerodynamic equations, first a minimum power for horizontal leveled flight at this altitude as a function of the UAV mass has been determined. With its current design, the UAV total mass including payload cannot exceed $16 \mathrm{~kg}$. To keep it as low as possible, a very light PEM fuel cell stack, capable of giving a maximum power over $700 \mathrm{~W}$ with a weight of only $3.82 \mathrm{~kg}$, has been considered. Considering the efficiency of all the elements in the powertrain, this stack can provide a stable power of $422.5 \mathrm{~W}$ to the propeller. With this power, gas reactant consumption has been estimated, and an analysis has been performed to determine if the UAV can transport the energy required to reach the desired altitude. To increase the available energy, the amount of gases has to be higher, but this implies increasing the aircraft mass and, consequently, the required power. These variables are coupled, and a solution is not always possible. A realistic system has been devised to store the reactant gases with a limited mass below $7 \mathrm{~kg}$. Results indicate that with its aerodynamic characteristics, the UAV should be capable of ascending up to $9,500 \mathrm{~m}$ at constant $R C$, and above $10,000 \mathrm{~m}$ at constant power with a maximum $R C$ of $0.88 \mathrm{~m} / \mathrm{s}$, with the described fuel cell and gas storage system.

\section{Acknowledgments}

This work has been partially funded by the Secretariat of State for Research of the Spanish Ministry of Economy and Competitiveness under project ENE2012-38642-C02-01/CON.

\section{References}

[1] M.F. Bento, Inside GNSS January-February (2008) 54-61.

[2] T.H. Bradley, B.A. Moffitt, D.N. Mavris, D.E Parekh, J. Power Sources 171 (2007) 793-801. 
[3] G.D. Rhoads, N.A. Wagner, B.J. Taylor, D.B. Keen, T.H. Bradley, AIAA paper 2010-6690 (2010) 8th Annual International Energy Conversion Engineering Conference, Nashville, USA.

[4] T. Kim, S. Kwon, Int. J. Hydrogen Energy 37 (2012) 615-622.

[5] G. K.Spyridon, J.A. Ekaterinaris, Aerosp. Sci. and Technol. 29 (2013) 339-350.

[6] ISO 3046-1 standard (1995) Geneva, Switzerland.

[7] S.M.C. Soares, J.R. Sodré, Proc. Inst. Mech. Eng. D - J. Aut. Eng. 216 (2002) 473-477.

[8] J.R. Sodré, S.M.C. Soares, J. Braz. Soc. Mech. Sci. \& Eng. 25 (2003) 279-28.

[9] J. Barranco, F. Barreras, A. Lozano, A.M. Lopez, V. Roda, J. Martin, M. Maza, G.G. Fuentes, E., Almandoz, Int. J. Hydrogen Energy, 35 (2010) 11489 - 11498.

[10] J. Barranco, F. Barreras, A. Lozano, M. Maza, M., J. Power Sources, 196 (2011) 044103-1 044103-7.

[11] ISO/TS 15869:2009 standard (2009) Geneva, Switzerland.

[12] S.T. Peters, Composites Materials and Processes, first ed. Digital Engineering Library McGraw Hill, Mountain View, California, 2004..

[13] S.W. Jorgensen, Current Opin. Solid State and Mater. Sci. 15 (2011) 39-43.

[14] A. Noth, Design of solar powered airplanes for continuous flight, Ph.D. Thesis, Autonomous System Lab, ETH Zürich, 2008. 


\section{Table captions}

Table 1. Summary of the main equations obtained from the aerodynamic analysis

Table 2. Gas storage cylinders considered in the analysis. 


\section{Figure captions}

Fig. 1. Different forces applied on the flying aircraft.

Fig. 2. Minimum required power for steady horizontal flight at $10,000 \mathrm{~m}$ as a function of the total UAV mass.

Fig. 3. Flight ceiling as a function of UAV total mass for a thrusting power of $422.5 \mathrm{~kW}$.

Fig. 4: Required power as a function of altitude for different constant $R C$. The dotted lines display the net power available in the propeller supplied by an ICE (decreasing line) and by a fuel cell (horizontal line).

Fig. 5. Ascending flight for constant rate of climb $R C$ (dotted lines) and for constant power (maximized $R C$ ).

Fig. 6. Maximum height as a function of mass for different available energy.

Fig. 7. Experimental polarization curve for a single cell with a Celtec ${ }^{\circledR}-P 1100 \mathrm{MEA}$.

Fig. 8. Energy losses in the different powertrain elements.

Fig. 9. Required $\mathrm{O}_{2}$ and $\mathrm{H}_{2}$ volumes stored at 500 bar as a function of height for an UAV of $16 \mathrm{~kg}$.

Fig. 10. Multi-parameter plot relating service ceiling, range, engine power and (constant) $R C$ for a total hydrogen volume of 41 at 500 bar.

Fig. 11. Multi-parameter plot relating service ceiling, range and engine power (constant) for a total hydrogen volume of 41 at 500 bar. 


\begin{tabular}{|c|c|c|}
\hline & Ascending segment $($ constant $R C)$ & Cruising segment \\
\hline Force $x$-axis & $T-W \operatorname{sen}(\beta)-D=m a_{x}$ & $T=D=\frac{1}{2} \rho v^{2} S C_{D}$ \\
\hline Force z-axis & $L-W \cos (\beta)=0$ & $L=W$ \\
\hline $\begin{array}{c}\text { Acceleration } \\
\text { x-axis }\end{array}$ & $a_{x}=\frac{\cos ^{2}(\beta)}{\sin (\beta)\left(2 \cos ^{2}(\beta)-\sin ^{2}(\beta)\right)} \frac{c R C^{2}}{A-h}$ & - \\
\hline $\begin{array}{c}\text { Flight } \\
\text { ceiling }\end{array}$ & $h=A-B\left[\frac{2}{C_{L} v_{\max }^{2}}\left(\frac{W}{S}\right)\right]^{1 / c}$ & - \\
\hline $\begin{array}{c}\text { Required } \\
\text { Power }\end{array}$ & $P=\frac{R C}{\sin (\beta)}\left\lfloor W \cos (\beta)\left(\frac{C_{D 0}}{C_{L}}+\frac{C_{L} S}{\pi e b^{2}}\right)+W \sin (\beta)+m a_{x}\right.$ & $\left.P=\sqrt{\frac{2}{\rho C_{L}} \frac{W^{3}}{S}\left(\frac{C_{D 0}}{C_{L}}+\frac{C_{L} S}{\pi e b^{2}}\right.}\right)$ \\
\hline
\end{tabular}




\begin{tabular}{|c|cccccccc|}
\hline Type & $\begin{array}{c}\text { Pressure } \\
(\mathbf{b a r})\end{array}$ & $\begin{array}{c}\mathbf{V}_{\mathbf{H} 2} \\
(\mathbf{l})\end{array}$ & $\begin{array}{c}\mathbf{V}_{\mathbf{O} 2} \\
(\mathbf{l})\end{array}$ & $\begin{array}{c}\mathbf{M}_{\mathbf{H} 2} \\
(\mathbf{k g})\end{array}$ & $\begin{array}{c}\mathbf{M}_{\mathbf{O} 2} \\
(\mathbf{k g})\end{array}$ & $\begin{array}{c}\mathbf{M}_{\text {total }} \\
(\mathbf{k g})\end{array}$ & $\mathbf{W h ~ k g}^{-\mathbf{1}}$ & $\mathbf{W h ~ I}^{\mathbf{1}}$ \\
\hline II & 300 & 6 & 3 & 7.91 & 4.92 & 15.40 & 67.18 & 113.44 \\
\hline III & 300 & 6 & 3 & 2.81 & 2.37 & 6.21 & 166.44 & 113.44 \\
\hline IV & 500 & 4 & 2 & 1.91 & 1.84 & 4.50 & 255.50 & 166.90 \\
\hline IV & 700 & 3 & 2 & 1.46 & 2.01 & 4.16 & 239.60 & 196.73 \\
\hline
\end{tabular}




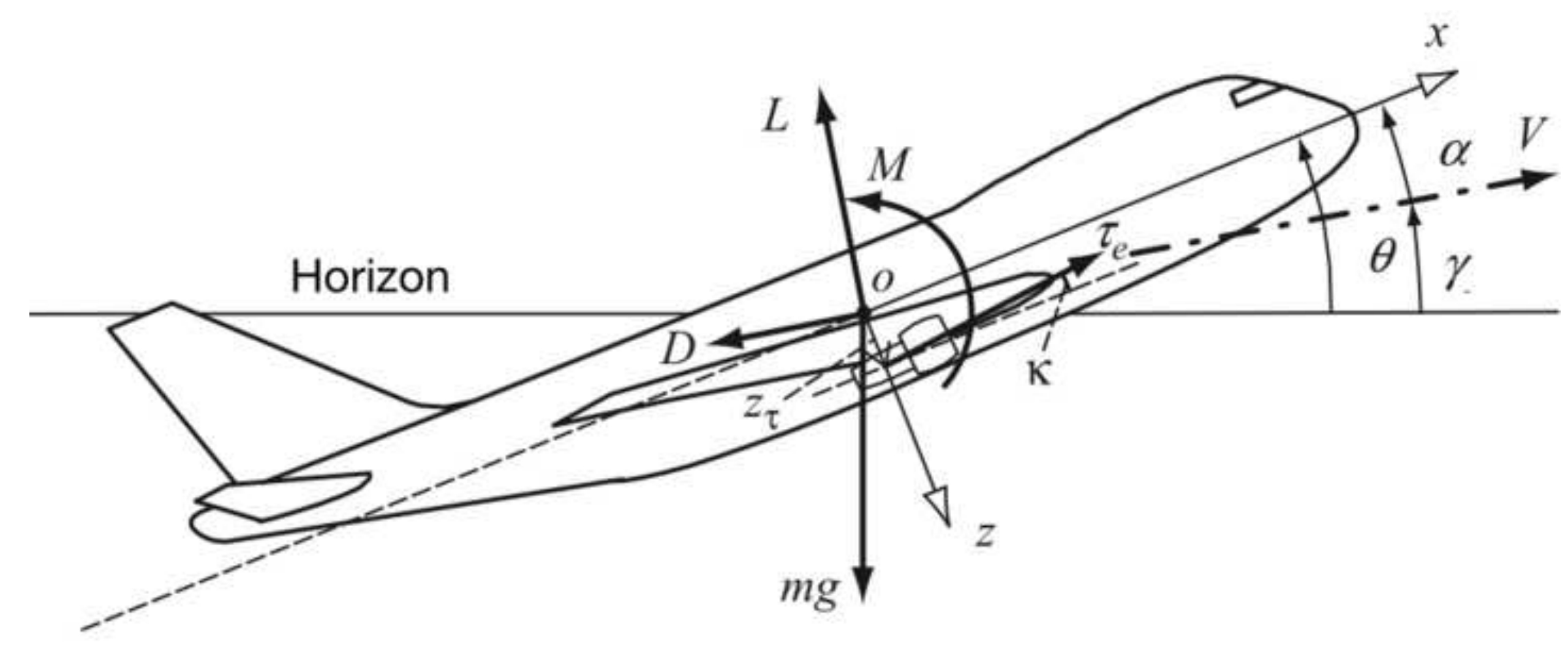




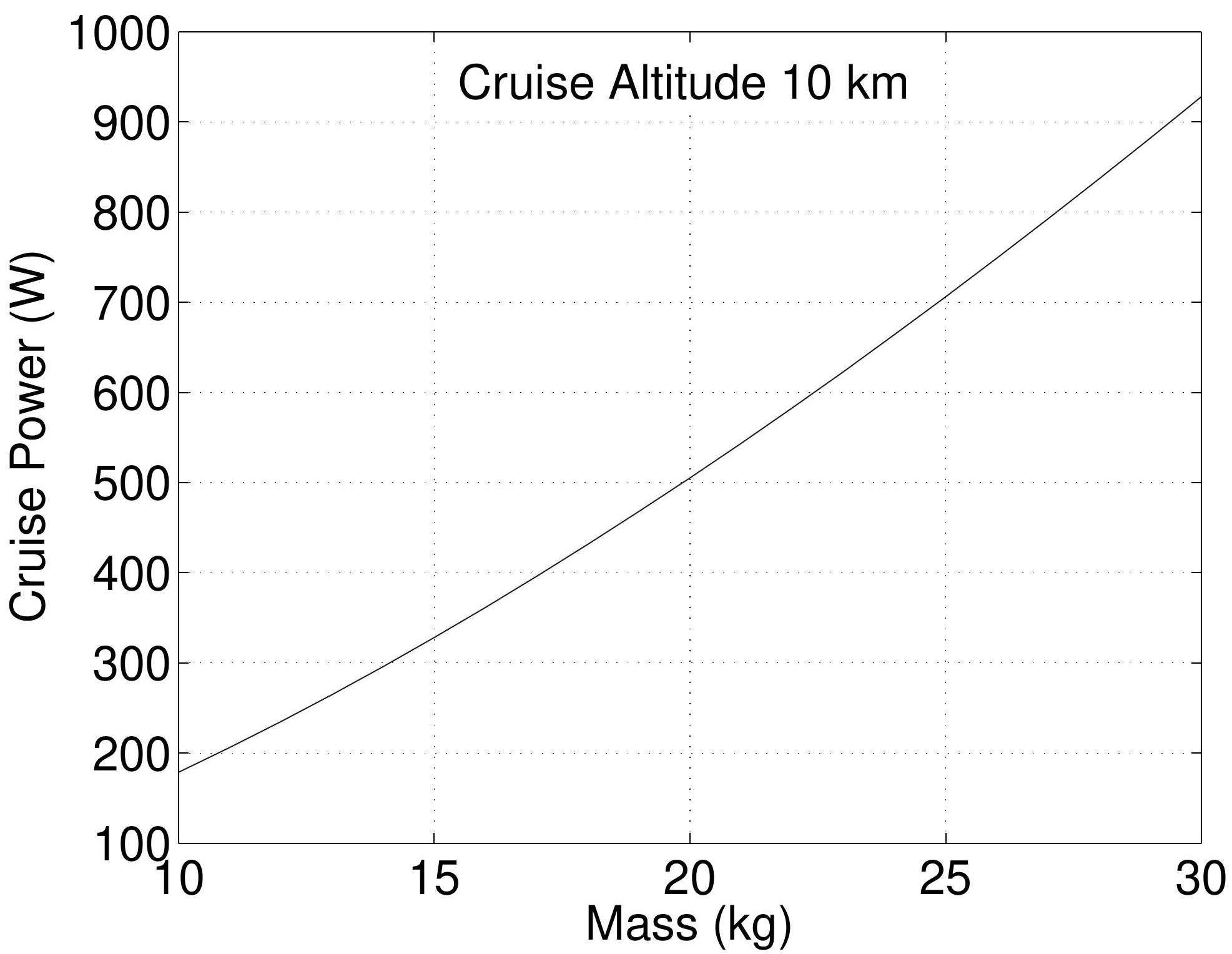




\section{Figure(s)}

Click here to download Figure(s): figure 3.eps

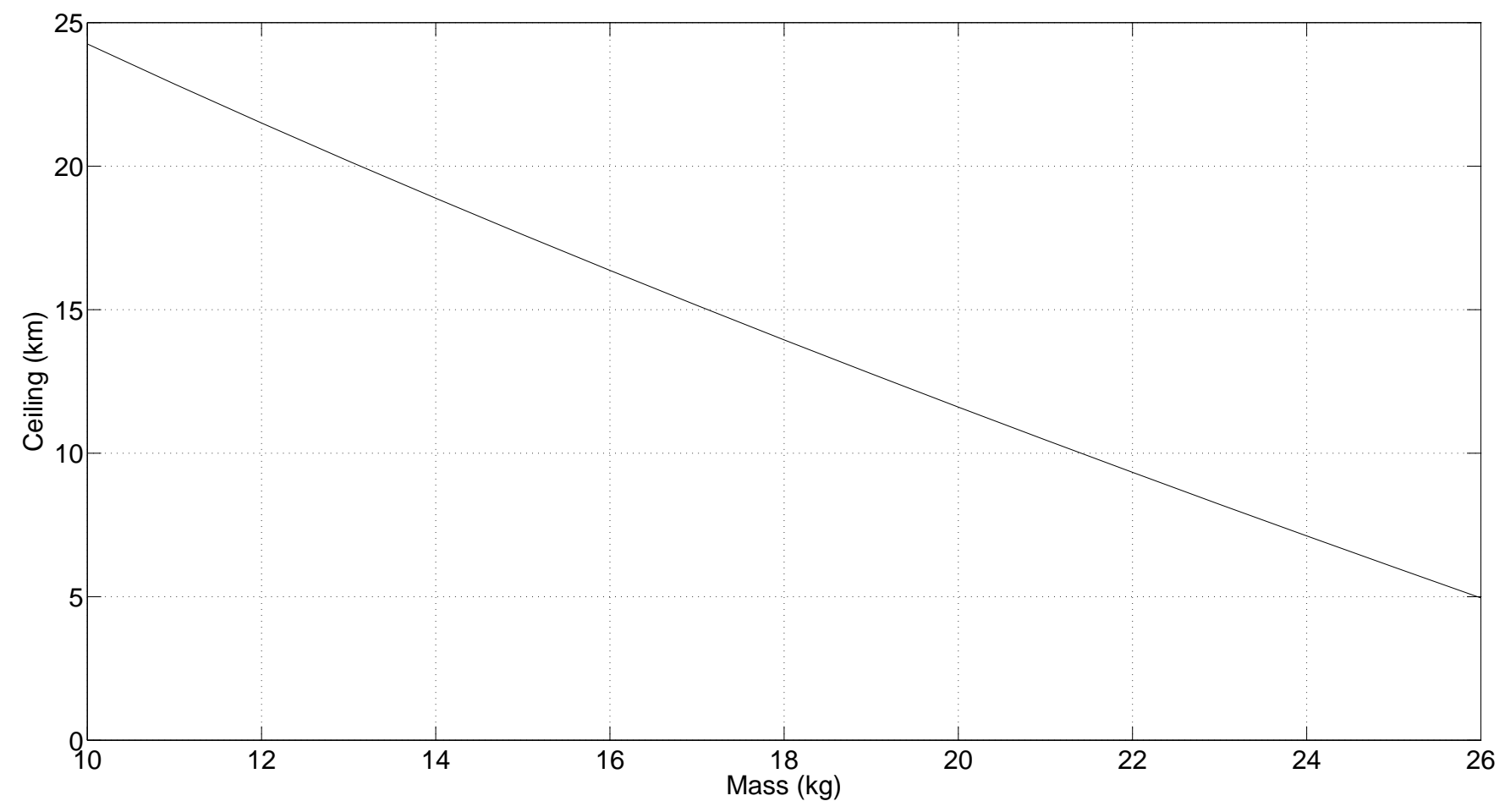




\section{Figure(s)}

Click here to download Figure(s): figure 4.eps

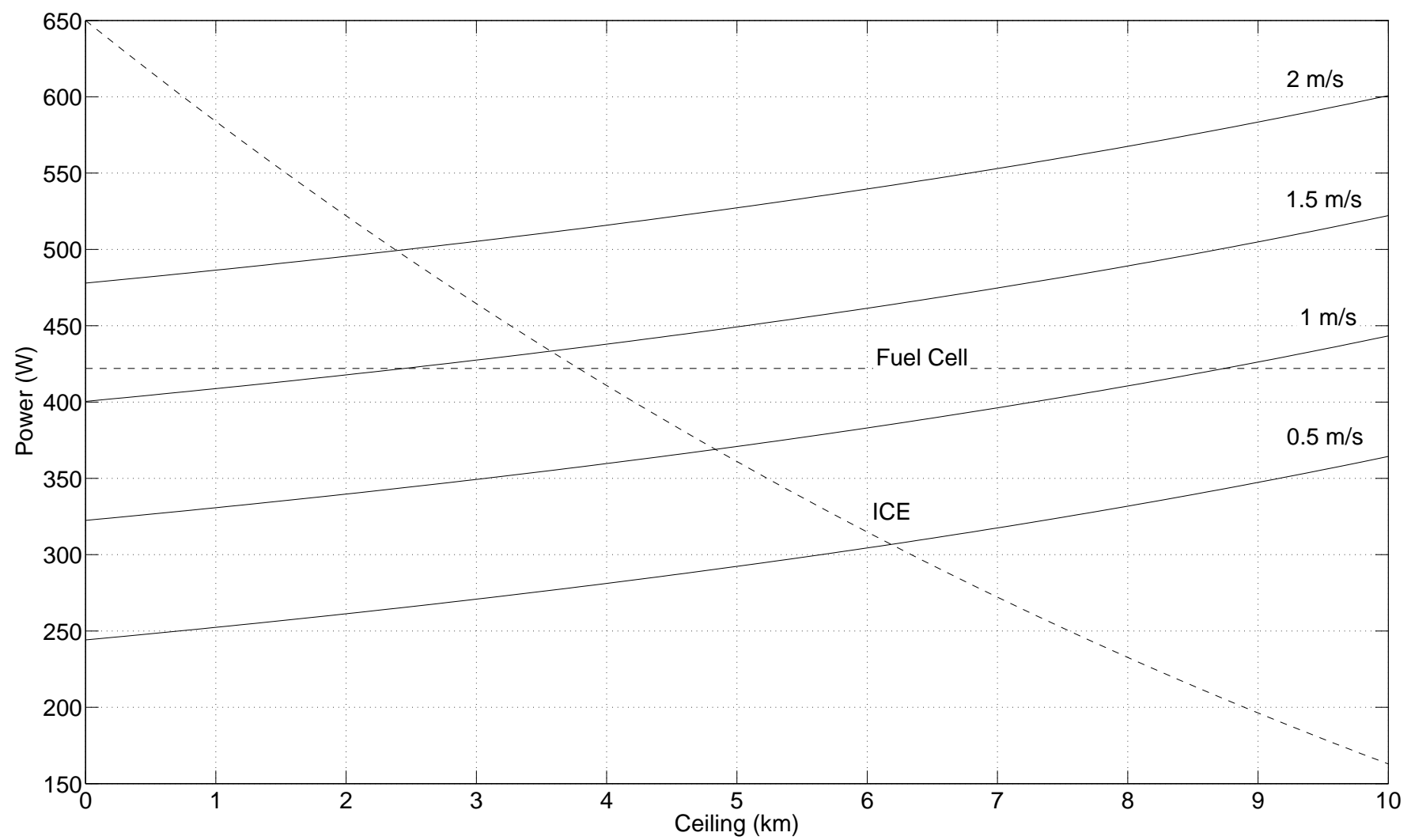




\section{Figure(s)}

Click here to download Figure(s): figure 5.eps
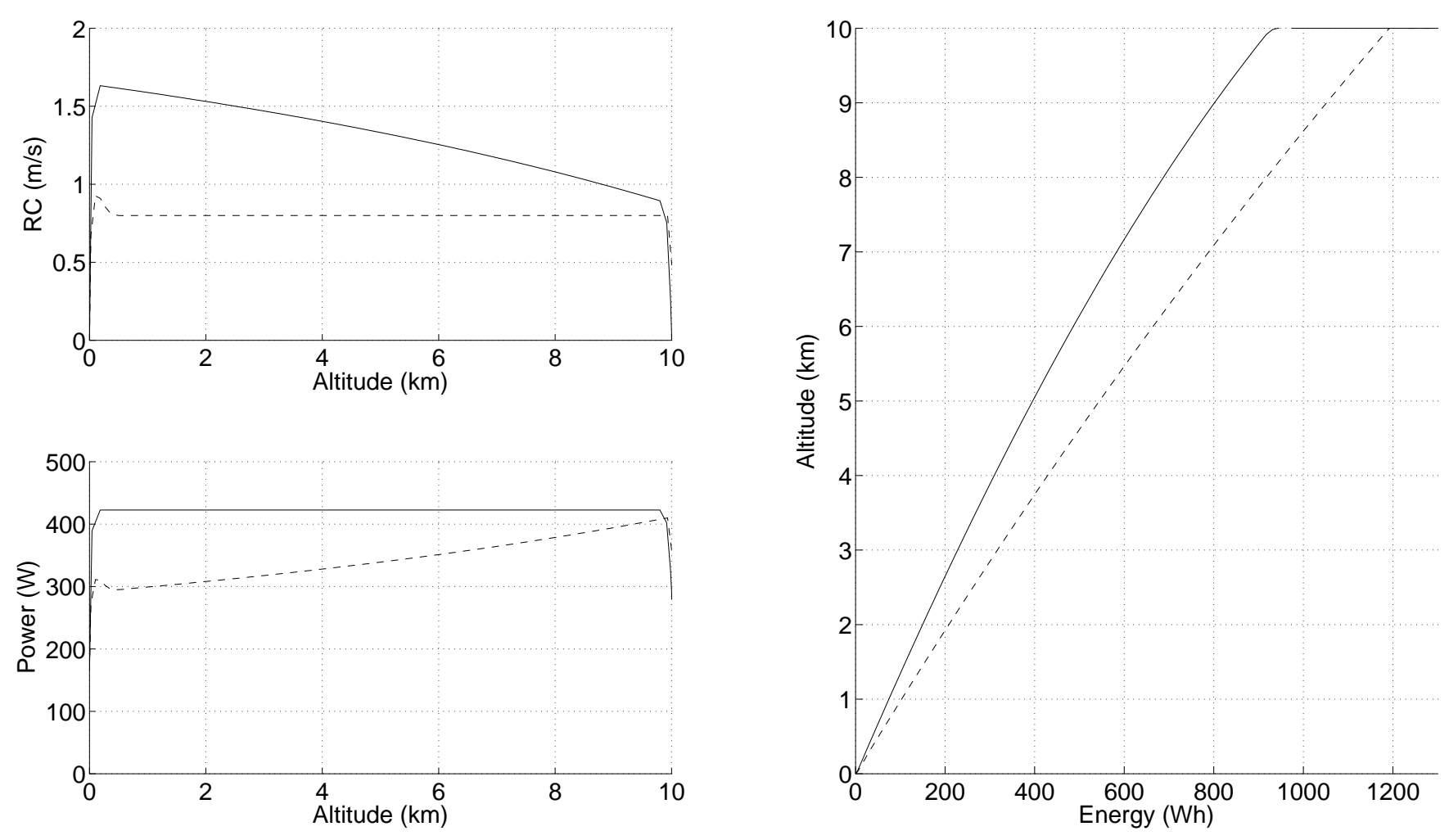


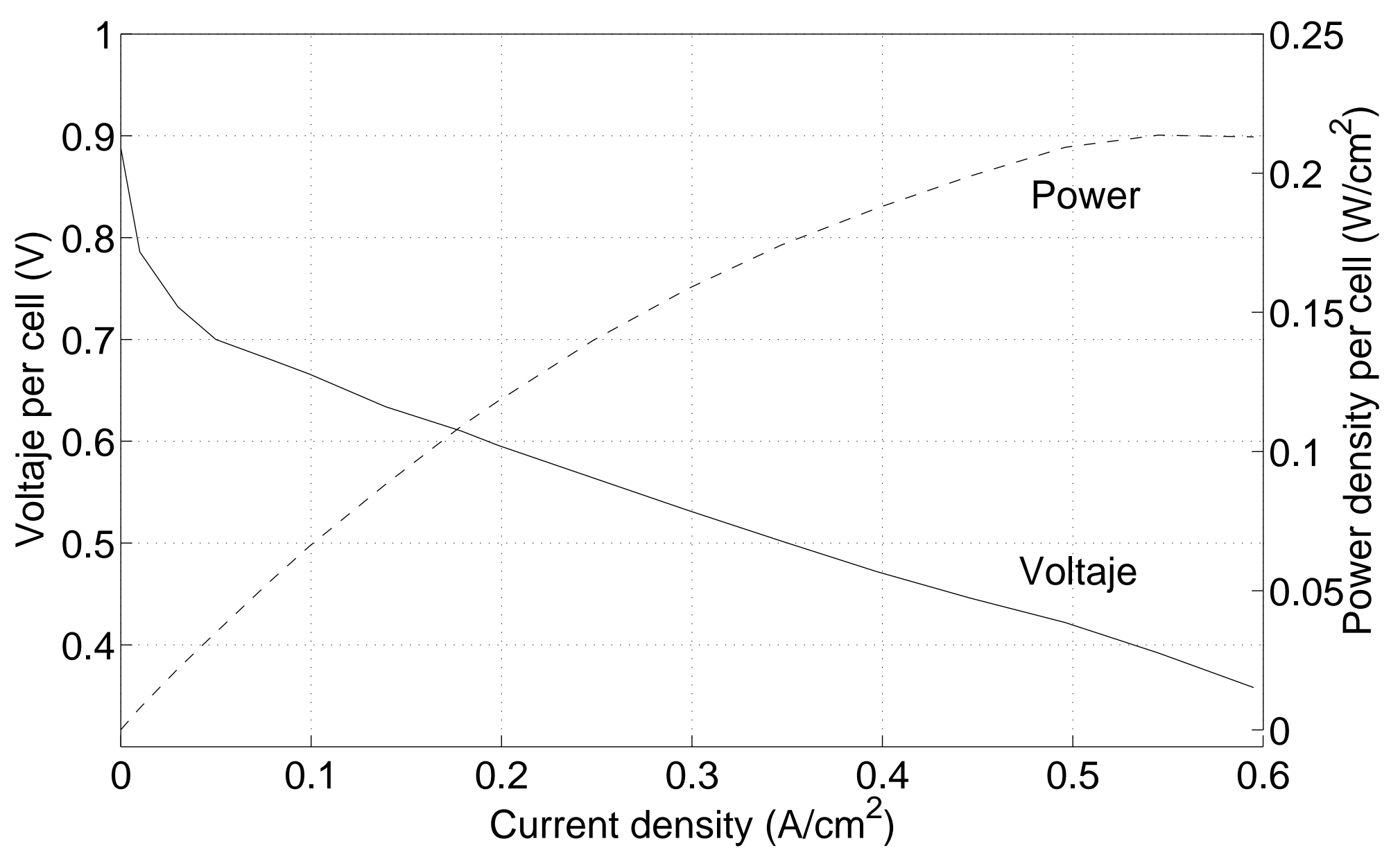




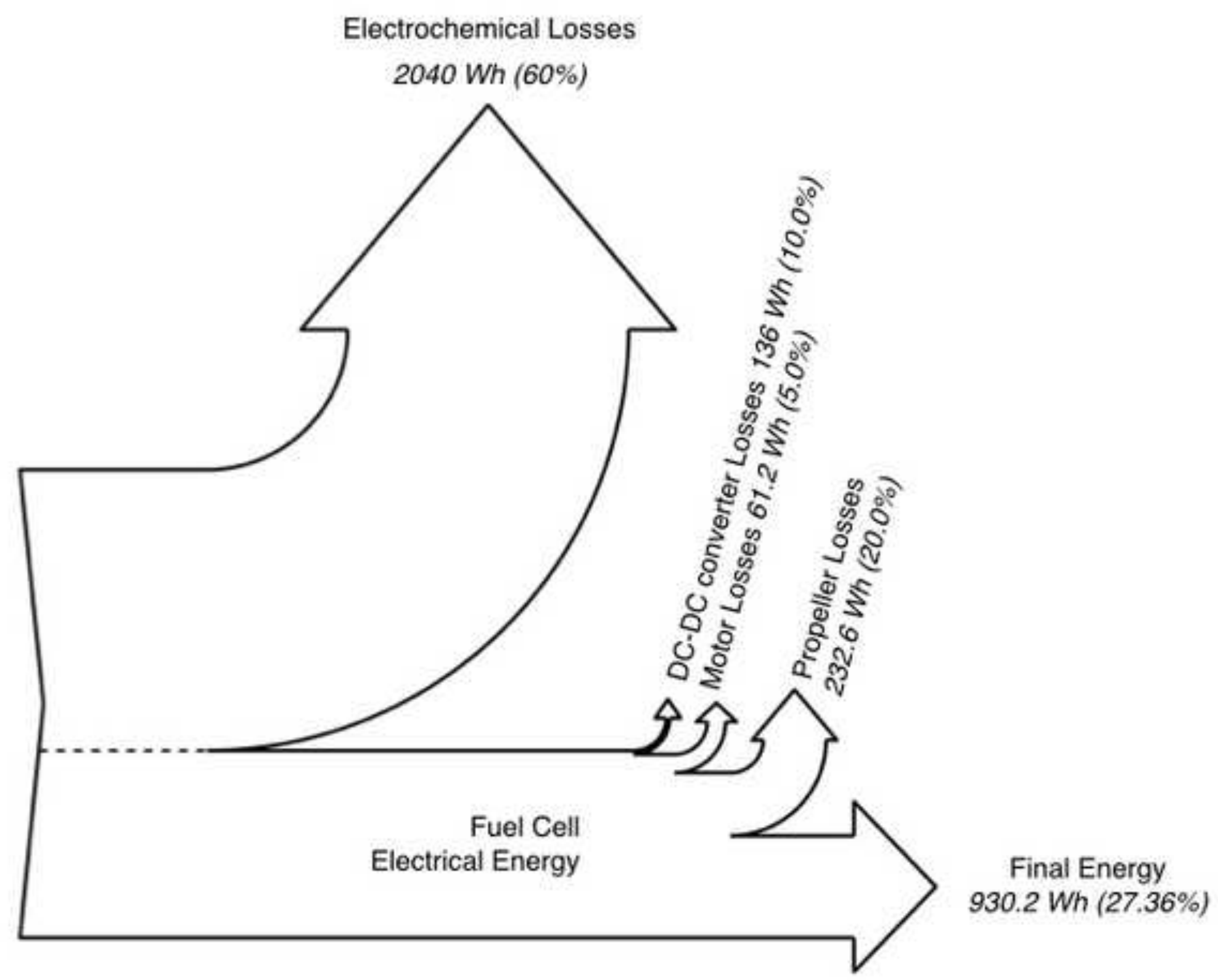




\section{Figure(s)}

Click here to download Figure(s): figure 9.eps

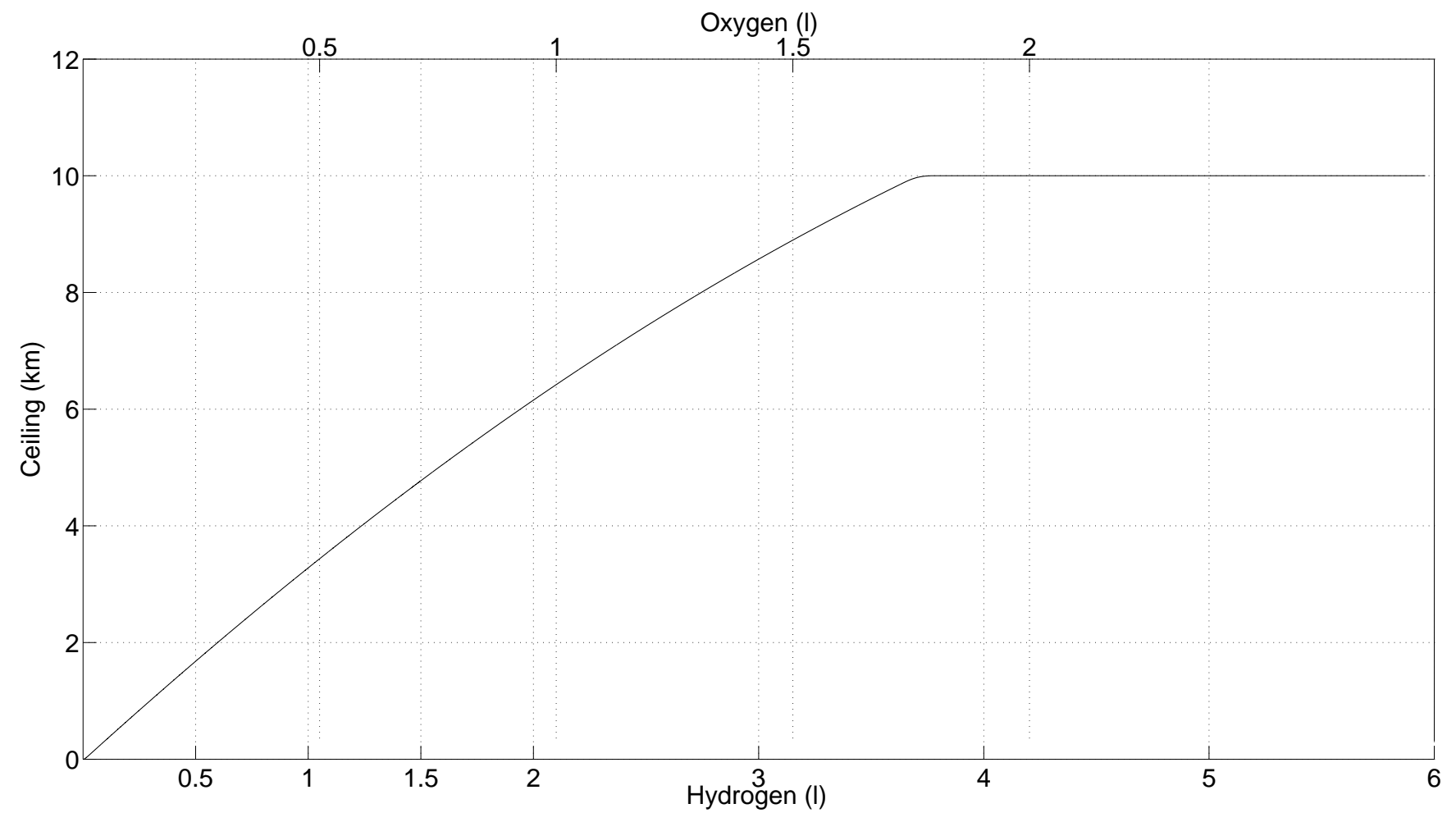


Click here to download high resolution image

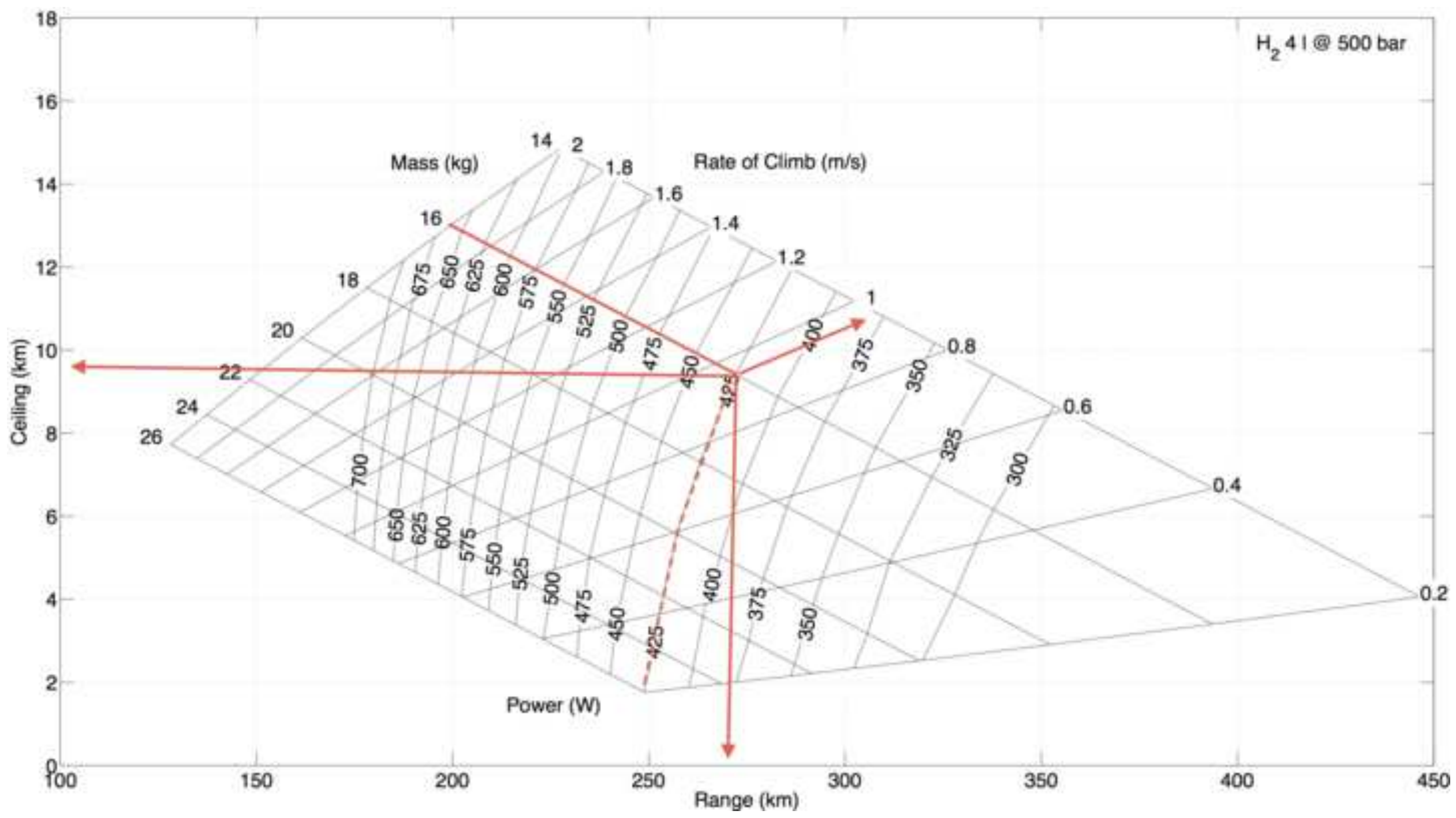




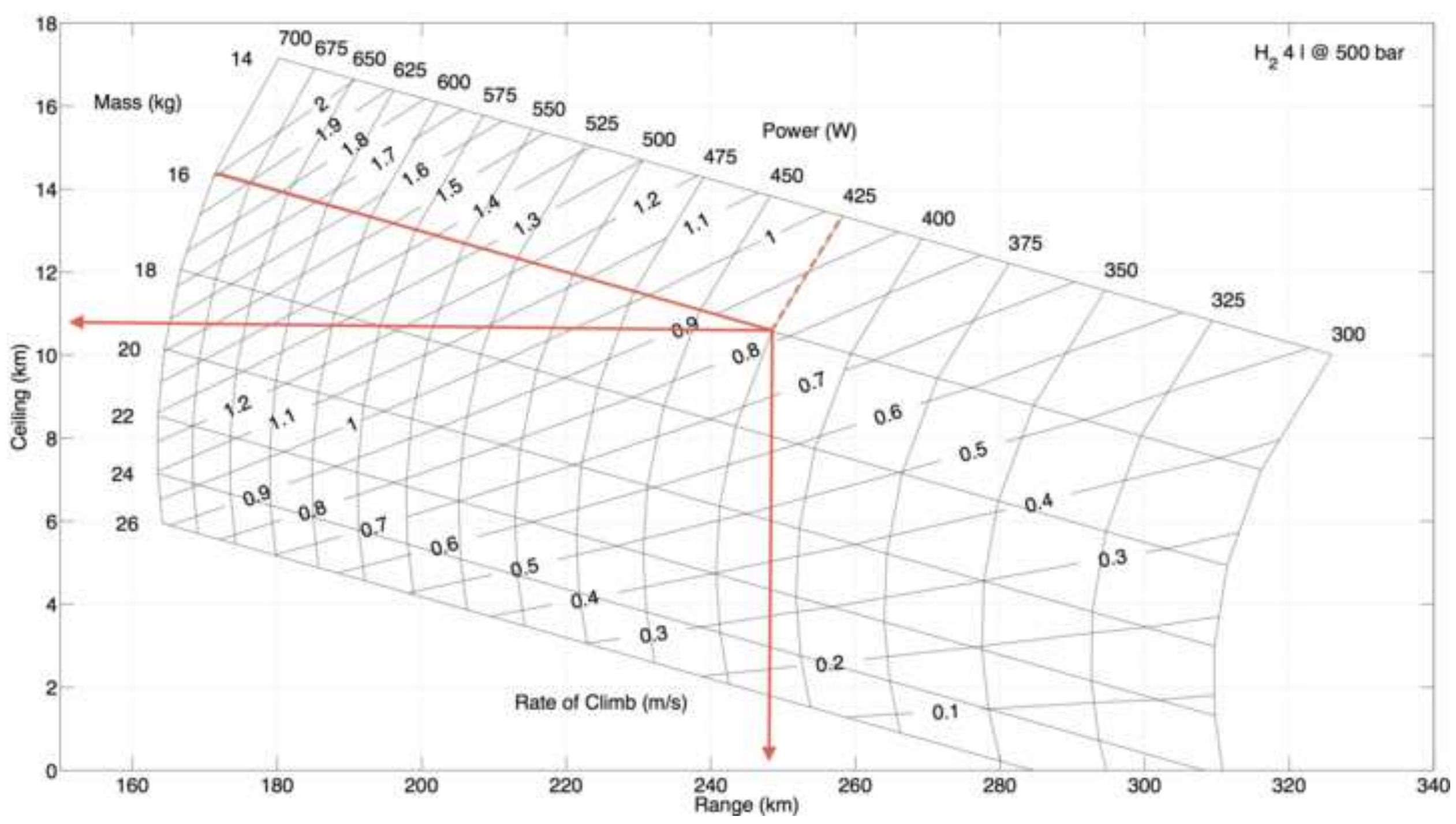

